Original article

\title{
Evaluation of professional autonomy and the association with individual factors among nurses in the Southeast of Iran
}

\author{
Mohadeseh Motamed-Jahromi ${ }^{1}$, Tayebe Jalali ${ }^{2}$ Fatemeh Eshghi $^{3}$, Homa Zaher ${ }^{4}$, Seyedeh Leila Dehghani ${ }^{*}$
}

(Received: 9 Aug 2015; Accepted: 31 Oct 2015)

\begin{abstract}
Background and Purpose: Professional autonomy in nursing is defined as working in a self-determined environment and making decisions based on professional judgment. This study aimed to evaluate professional autonomy and its association with individual factors in nurses employed at teaching hospitals affiliated to Kerman University of Medical Sciences in the southeast of Iran in 2013.

Methods: This was a descriptive analytical study, and required data were collected by quota sampling using self-administered questionnaires, which were completed by 385 nurses at four teaching hospitals in Kerman, Iran. Data analysis was performed using inferential (ANOVA) and descriptive statistics (mean and frequency) in SPSS V.18.

Results: In this study, a significant correlation was observed between professional autonomy and age $(\mathrm{P}>0.001)$, gender $(\mathrm{P}=0.04)$, work experience $(\mathrm{P}>0.03)$, education level $(\mathrm{P}>0.02)$ and attitude of nurses. Moreover, a positive correlation was found between the mean scores of professional autonomy and nursing experience $(\mathrm{r}=0.559)$.

Conclusion: According to the results of this study, general attitude of nurses towards professional autonomy was relatively positive. In addition, professional autonomy was observed to increase with higher education level and job satisfaction. Hierarchical team decisionmaking may restrict professional autonomy in nurses. Therefore, it is recommended that nursing skills and professional autonomy of nurses be improved through appropriate methods.
\end{abstract}

Keywords: Attitude, Nurse, Practice, Professional autonomy

\section{Introduction}

Autonomy is a leading concept in the current literature available on medical and nursing practice (1). Nursing practice encompasses autonomous and cooperative provision of care for patients of different age groups with diverse family and social backgrounds in all clinical settings (2). According to the literature, clinical autonomy plays a pivotal role in the job satisfaction of nurses (3). This parameter is an essential part of professional practice and judgment and identifies as the freedom of autonomous practice at professional settings (4).

A mature individual is self-determining and capable of rational decision-making (5). As such, autonomy enables individuals to find a direction, reflect on the matter at hand and finally, make an appropriate decision (6). Autonomy in decisionmaking has been recognized as an inherent part of professional practice in different occupations (7).

Engaging in professional practice in environments with high demand and poor authority supervision

\footnotetext{
${ }^{1}$ Fasa University of Medical Sciences, Fasa, Iran

${ }^{2}$ Disaster Management and Emergency Center, Kerman University of Medical Sciences, Kerman, Iran

${ }^{3}$ Hormozgan University of Medical Sciences, Bandar Abbas, Iran

${ }^{4}$ Shiraz University of Medical Sciences, Shiraz, Iran

$5,{ }^{*}$ Corresponding author: Department of Public Health, Behbahan Faculty of Medical Sciences, Behbahan, Iran. Email: dehganil@yahoo.com
} 
could expose nurses to a higher risk of stress disorders, major depression and absenteeism (8). Other factors such as substantial job pressure, low autonomy and poor empowerment are considered as major causes of nurse turnover (9).

In recent years, autonomy has been defined as the implementation of obligation accompanied with motivation in order to induce persistence in nurses (10). Inadequate professional autonomy could be associated with inappropriate instructions at work environment (11). In other words, nursing curriculum programs established to train these individuals with necessary skills can barely encourage contemplation and autonomous performance in nursing students (12). Owing to the fact that autonomy is the cornerstone of any profession, nurses all over the world are focused on the reinforcement of their professional status by increasing their education level and clinical autonomy $(7,13)$.

Several studies have evaluated the status of nursing autonomy in different regions of the world. For instance, a study conducted on the nursing staff of intensive care units in Greece reported average autonomy in technical tasks, as well as low level of professional autonomy in independent decision-making of nurses (14). According to a review of previous studies on professional autonomy, personal traits of nurses are likely to affect professional autonomy (15). In another research, level of professional autonomy was compared between nurses in Egypt and Saudi Arabia, and the findings were indicative of lower level of autonomy in Egyptian nurses. This could be due to the large number of patient referrals, which would lead to heavy workload and lack of time for these nurses to fulfill their responsibility (16).

In this regard, Iranian researchers have applied qualitative methods to assess autonomy among nurses, proposing factors such as proficiency, self-confidence, organizational framework, education level and professional support to be effective in the improvement of autonomy and clinical decision-making (17). It is noteworthy that professional experience could increase self-confidence, efficiency and autonomy in putting theoretical knowledge into practice in different occupations (18).

On the other hand, Iranian nurses believe that nursing empowerment is a result of professional interactions, collective characteristics, and organizational culture and structure at work environment (19). According to previous studies, parameters such as lack of nursing authority, heavy workload and insufficient resources are likely to restrict the practice of evidence-based nursing (20). Therefore, it could be concluded that increased nursing knowledge and skills will result in the empowerment of nursing professionals. Furthermore, improvement of authority and self-confidence could be effective in the autonomous application of nursing knowledge (21).

In Iran, few studies have assessed nursing professional autonomy through quantitative methods. The present study aimed to evaluate professional autonomy and its association with individual factors among nurses in the southeast of Iran in 2013 using quantitative methods. It was hypothesized that attitude of nurses towards professional autonomy was correlated with demographic data. Findings of our study could provide significant input regarding the attitude of Iranian nurses towards professional autonomy.

\section{Materials and methods}

This cross-sectional study was conducted on nurses employed at different wards of four teaching hospitals affiliated to Kerman University of Medical Sciences in the southeast of Iran in 2013. In total, 385 nurses were selected from a population of 768 nurses by quota sampling using Cochran's formula. Questionnaires were randomly distributed among nurses in each ward. Inclusion criteria of the study were bachelor's or master's degree of nursing and at least six months of clinical work experience.

Data were collected using two-part innominate questionnaires. First section of the questionnaire focused on the demographic data of participants, which were classified into two categories of personal data (e.g., age, gender, marital status and education level) and professional data (e.g., clinical experience and workplace). Second section of the questionnaire was self-administered and designed based on the findings of previous studies to evaluate the attitude of nurses towards professional autonomy $(4,10,22,23)$. This section consisted of 19 items that were scored 
on a five-point Likert scale, as follows: strongly agree (score one), partly agree (score two), do not know (score three), partly disagree (score four) and strongly disagree (score five).

For assessing qualitative face validity, all items of the questionnaire were reviewed by a panel of ten experts in terms of syntax, appropriateness, difficulty, relevance and ambiguity, and some alterations were made to the words and phrases of questionnaire. Content validity of the questionnaire was determined using content validity index (CVI). Moreover, ten experts confirmed CVI of questionnaire items at 0.86 , in terms of relevance, clarity and simplicity. Reliability of the questionnaire was determined at $77 \%$ using internal consistency analysis (Cronbach's alpha) for 30 nurses before data collection. Attitude of participants towards each item in the questionnaire was scored based on the mean score of each question and compared with the sequential index, as follows: negative attitude (scores 1 and 2), moderately negative attitude (scores 2 and 3), ambivalent attitude (score 3), moderately positive attitude (scores 3 and 4 ) and positive attitude (scores 4 and 5). In this process, The permission to conduct this study was obtained from the presidents of the studied hospitals in Kerman.
Questionnaires were completed by nurses after obtaining verbal permission from the chief of wards. Data analysis was performed in SPSS V.18 using descriptive and analytic statistics. Descriptive statistics comprised of frequency counts, reliability and means of data. In addition, relationship between the mean of attitude scores and demographic variables was assessed using one-way analysis of variance (ANOVA). Our study protocol was approved by the Research Affairs at Kerman University of Medical Sciences (research number: 92/209, ethical code: k/92/209). Also, participants were granted terms of confidentiality and anonymity after providing written consent from nurses and hospital authorities. Objectives of the study and content of questionnaires were explained to the participants, and they were allowed to enquire about census sampling and research procedures. Participation in the present study was voluntary, and completion of questionnaires lasted for 5-10 minutes on average.

\section{Results}

In total, 385 nurses were enrolled in this study, and 372 participants completed the questionnaires.

Table 1. Mean scores of autonomy based on demographic characteristics of nurses

\begin{tabular}{|c|c|c|c|c|c|}
\hline Demographic Characteri & & $\mathbf{N}$ & $\%$ & Mean Score of Autonomy & P-value \\
\hline \multirow{3}{*}{ Age (year) } & $<30$ & 184 & 49.2 & 3.85 & \multirow{3}{*}{$<0.001$} \\
\hline & $30-40$ & 151 & 40.4 & 4.07 & \\
\hline & $>40$ & 27 & 7.2 & 4.11 & \\
\hline \multirow{4}{*}{ Health Center } & One & 129 & 34.6 & 3.87 & \multirow{4}{*}{$<0.001$} \\
\hline & Two & 112 & 30 & 4.03 & \\
\hline & Three & 106 & 28.4 & 3.84 & \\
\hline & Four (Psychiatric Clinic) & 25 & 6.7 & 4.3 & \\
\hline \multirow{2}{*}{ Gender } & Female & 348 & 93.5 & 3.95 & \multirow{2}{*}{0.04} \\
\hline & Male & 24 & 6.4 & 4.07 & \\
\hline \multirow{2}{*}{ Marital Status } & Single & 138 & 37.09 & 3.98 & \multirow{2}{*}{0.14} \\
\hline & Married & 230 & 61.8 & 4.04 & \\
\hline \multirow{2}{*}{ Education Level } & Bachelor's Degree & 364 & 97.8 & 3.89 & \multirow{2}{*}{0.02} \\
\hline & Master's Degree & 5 & 1.3 & 4.13 & \\
\hline \multirow{3}{*}{ Clinical Work Experience } & 6 months- 10 years & 260 & 69.8 & 3.88 & \multirow{3}{*}{0.03} \\
\hline & $10-20$ years & 90 & 24.1 & 4.09 & \\
\hline & 20-30 years & 17 & 4.5 & 4.14 & \\
\hline \multirow{3}{*}{ Hospital Ward } & Intensive Care Unit & 139 & 37.3 & 4.04 & \multirow{3}{*}{0.04} \\
\hline & General Ward & 202 & 54.3 & 3.89 & \\
\hline & Psychiatric Ward & 28 & 7.5 & 4.09 & \\
\hline
\end{tabular}


Table 2. Mean scores of attitude towards professional autonomy in nurses

\begin{tabular}{|c|c|c|}
\hline & Mean & Attitude \\
\hline Proper Professional Autonomy & 3.25 & Relatively Positive \\
\hline Adequate Knowledge for Independent Decision-making & 4.51 & Positive \\
\hline Improved Professional Autonomy through Increased Clinical Experience and Nursing Skills & 4.17 & Positive \\
\hline Higher Autonomy Leads to Better Patient Advocacy & 4.20 & Positive \\
\hline Higher Autonomy Leads to Increased Job Satisfaction & 3.83 & Relatively Positive \\
\hline Satisfaction with Level of Autonomy at Different Wards & 2.95 & Relatively Negative \\
\hline Interest for Employment at Wards with Higher Professional Autonomy & 4.32 & Positive \\
\hline Increased Professional Autonomy Results in Elevated Self-confidence & 4.22 & Positive \\
\hline Better Nursing Knowledge Increases Professional Autonomy & 4.10 & Positive \\
\hline Better Control over Clinical Situations with Higher Autonomy & 4.02 & Positive \\
\hline Better Clinical Decision-making with Increased Professional Autonomy & 4.13 & Positive \\
\hline Better Quality of Patient Care with Increased Autonomy & 4.12 & Positive \\
\hline Increased Sense of Responsibility with Higher Autonomy & 3.84 & Relatively Positive \\
\hline Need to Receive Training on Nursing Knowledge and Skills to Increase Autonomy & 4.15 & Positive \\
\hline Decreased Nursing Autonomy due to Authority of Physicians & 4.18 & Positive \\
\hline Ignoring Decision-making and Autonomy of Nurses in Inter-professional Teamwork & 4.10 & Positive \\
\hline Lower Levels of Professional Autonomy in Iranian Nurses Compared to Other Countries & 3.84 & Relatively Positive \\
\hline Need for Improving Autonomy to Increase Professionalism in Nursing Staff & 4.08 & Positive \\
\hline Better Attitude of Society towards Nurses with Increased Professional Autonomy & 4.16 & Positive \\
\hline
\end{tabular}

Correspondingly, rate of responsiveness was estimated at $96.6 \%$. Assessment of demographic data indicated the age range of participants to be 22-55 years, with mean age of 30 years (Table 1). Moreover, age frequency statistics revealed that $93.5 \%$ of participants were female, $61.8 \%$ were married, and $97.8 \%$ had bachelor's degree of nursing. Also, $69.8 \%$ of the studied nurses had clinical work experience of six months to 10 years, and $54.3 \%$ of the study populations were employed at general wards.

In this study, mean score of attitude towards professional autonomy was calculated at 4.1 among participants. In addition, a statistically significant difference was observed between mean scores of professional autonomy and gender $(\mathrm{P}=0.04)$, age $(\mathrm{P}<0.001)$, work experience $(\mathrm{P}=0.03)$, employment at different wards $(\mathrm{P}=0.04)$, engagement at different hospitals $(\mathrm{P}<0.001)$ and education level of nurses $(\mathrm{P}=0.02)$ (Table 1). Mean scores of attitude towards each item of questionnaires are shown in Table 2. According to the results of Pearson's correlationcoefficient, there was a significant positive correlation between the mean of total autonomy scores and clinical experience of nurses $(\mathrm{r}=0.559)$.

\section{Discussion}

According to the results of the present study, nurses had a relatively positive attitude towards professional autonomy. It was observed that nurses were inclined towards higher professionalism in terms of independent decision-making and support of patients at clinical settings. It is noteworthy that by increasing professional autonomy, self-confidence and job satisfactions of nurses improved inadvertently.

Further results of this study indicated that professional autonomy was directly correlated with age and clinical experience of nurses. As a result, factors such as professional skills, job stability and adjustment with working conditions significantly enhanced, and nurses were more capable of fulfilling their duty at their health organization. A qualitative study performed in Thailand reported age and work experience to play a pivotal role in the enhancement of professional autonomy in nurses (15).

Furthermore, the findings indicated that higher education levels couldresultinimproved professional autonomy. Owing to the fact that clinical decisionmaking and self-management depend on the level of nursing knowledge, increased knowledge of nursing practice could result in the improvement of 
skills such as critical thinking, problem solving and independent decision-making. One study conducted in this regard reported high education level to be a major predictor for professional autonomy in clinical decision-making and performing technicoclinical tasks in nursing (16).

Additionally, the majority of nurses claimed that improved professional autonomy led to increased job satisfaction. This could be due to the increased sense of responsibility in nurses; as such, nurses will be individually accountable for their tasks throughout different clinical processes. Findings of another study in this regard reported professional autonomy as a significant predictor for job retention and satisfaction among nursing staff (10). Correspondingly, the majority of nurses claimed that increased professional autonomy helped them to support patients with vulnerable conditions more effectively. Therefore, it could be concluded that with increased autonomy, patient advocacy noticeably improves, and nurses could perform more autonomously in the presence of desirable clinical conditions. These findings are in line with the results obtained by Stewart et al., which indicated that professional autonomy of nurses is directly correlated with patient support (23).

Furthermore, they observed that nurses employed at psychiatric and intensive care wards had higher professional autonomy, as well as a more positive attitude towards their medical practice. Higher autonomy of nurses at psychiatric wards could be due to a number of reasons, such as the relationship between patients and nursing staff and superior control of nurses over the special conditions of the ward. In other words, nurses are mainly in charge of medical care in psychiatric wards compared to other health sections.

According to our participants, inter-professional teamwork and hierarchical decision-making were major restrictions for professional autonomy in nursing practice. In teamwork, a few professional figures, especially physicians, are expected to make major decisions for medical procedures, and this could diminish empowerment in nurses and they might feel that their autonomy is restricted by principles of teamwork (7).

\section{Conclusion}

In conclusion, results of the current study indicated that general attitude of nurses towards professional autonomy was satisfactory in the selected health centers. Increased sense of professional autonomy could effectively improve job satisfaction, self-confidence and management of different tasks in nursing staff. This could be achieved through enhancing the level of nursing knowledge and professional skills required for nursing practice. Furthermore, medical authorities at health centers should attempt to improve professional autonomy in nursing staff, which will ultimately influence the outlook of society towards nursing practice.

One of the limitations of the present study was the relatively small sample size. In addition, this research was conducted in only one of the cities of Iran; therefore, the findings could not be generalized to all populations. It is recommended that future studies be performed as to identify the challenges against improving professional autonomy in nurses, as well as to devise new strategies to overcome these obstacles.

\section{Conflict of interest}

None declared.

\section{Authors' contributions}

M Motamed-Jahromi was responsible for the design of the questionnaires and preparation of the final manuscript. SL Dehghani performed statistical analyses and F Eshghi proposed the study subject. $\mathrm{T}$ Jalali and $\mathrm{H}$ Zaher performed data collection and analysis in SPSS.

\section{Acknowledgements}

This article was extracted from a research project approved by the Deputy of Research at Kerman University of Medical Sciences with ethical code of $\mathrm{k} / 92 / 292$. Hereby, we extend our gratitude to all the nurses for their participation in this study. 


\section{References}

1. Mackenzie C. Relational autonomy, normative authority and perfectionism. J Soc Philos 2008; 39(4):512-33.

2. Fantahun A, Demessie A, Gebrekirstos K, Zemene A, Yetayeh $\mathrm{G}$. A cross sectional study on factors influencing professionalism in nursing among nurses in Mekelle Public Hospitals, North Ethiopia, 2012. BMC Nurs 2014; 13:10.

3. Kovner C, Brewer C, Wu YW, Cheng Y, Suzuki M. Factors associated with work satisfaction of registered nurses. J Nurs Scholarsh 2006; 38(1):71-9.

4. Thompson MC. Professional autonomy of occupational health nurses in the United States. Workplace Health Saf 2012; 60(4):159-65.

5. Christman J. Relational autonomy, liberal individualism, and the social constitution of selves. Philos Stud 2004; 117(1):143-64.

6. Taylor JS. Practical Autonomy and Bioethics. $1^{\text {st }}$ ed. London: Routledge; 2009.

7. Traynor M, Boland M, Buus N. Professional autonomy in 21st century healthcare: nurses' accounts of clinical decision-making. Soc Sci Med 2010; 71(8):1506-12.

8. Enns V, Currie S, Wang J. Professional autonomy and work setting as contributing factors to depression and absenteeism in Canadian nurses. Nurs Outlook 2015; 63(3):269-77.

9. Hayes LJ, L O'Brien-Pallas L, Duffield C, Shamian J, Buchan J, Hughes F, et al. Nurse turnover: a literature review-an update. Int J Nurs Stud 2012; 49(7):887-905.

10. Unruh L, Zhang NJ. The role of work environment in keeping newly licensed RNs in nursing: A questionnaire survey. Int J Nurs Stud 2013; 50(12):1678-88.

11. Karagözoğlu S. Nursing students level of autonomy: a study from Turkey. Nurse Educ Today 2009; 29(2):176-87.

12. Karagozoglu S. Level of autonomy of Turkish students in the final year of university baccalaureate degree in health related fields. Nurs Outlook 2008; 56(2):70-7.

13. Suominen T, Leino-Kilpi H, Merja M, Doran DI, Puukka P. Staff empowerment in Finnish intensive care units. Intensive Crit Care Nurs 2001; 17(6):341-7.

14. Papathanassoglou ED, Tseroni M, Karydaki A, Vazaiou G, Kassikou J, Lavdaniti M. Practice and clinical decisionmaking autonomy among Hellenic critical care nurses. J Nurs Manag 2005; 13(2):154-64.

15. Supametaporn P. The conceptualization of professional nurse autonomy. J Nurs Sci 2013; 31(1):80-6.

16. Dorgham ShR, Al.Mahmoud SA. Leadership styles and clinical decision making autonomy among critical care nurses: a comparative study. IOSR J Nurs Health Sci 2013; 1(4):71-83.

17. Adib-Hagbaghery M, Salsali M, Ahmadi F. The factors facilitating and inhibiting effective clinical decision-making in nursing: a qualitative study. BMC Nurs 2004; 3:2.

18. Adib-Hajbaghery M. Evidence-based practice: iranian nurses' perceptions. Worldviews Evid Based Nurs 2009; 6(2):93-101.

19. Adib-Hagbaghery M, Salsali M. A model for empowerment of nursing in Iran. BMC Health Serv Res 2005; 5:24.

20. Adib-Hajbaghery M. Factors facilitating and inhibiting evidence-based nursing in Iran. J Adv Nurs 2007; 58(6):566-75

21. Adib-Hajbaghery M, Salsali M, Ahmadi F. A qualitative study of Iranian nurses' understanding and experiences of professional power. Hum Resour Health 2004; 2 (1):9.

22. Karagözoğlu S. Nursing students level of autonomy: a study from Turkey. Nurse Educ Today 2009; 29(2):176-87.

23. Stewart J, Stansfield K, Tapp D. Clinical nurses' understanding of autonomy: accomplishing patient goals through interdependent practice. J Nurs Adm 2004; 34(10):443-50. 